\title{
'Murasaki-29' Sweetpotato
}

\author{
Don R. La Bonte ${ }^{1,6}$, Arthur Q. Villordon², Christopher A. Clark ${ }^{3}$, \\ and Paul W. Wilson ${ }^{4}$ \\ Louisiana Agricultural Experiment Station, Louisiana State University \\ Agricultural Center, Baton Rouge, LA 70803
}

\author{
C. Scott Stoddard ${ }^{5}$ \\ University of California Cooperative Extension, 2145 Wardrobe Avenue, \\ Merced, CA 95340
}

Additional index words. vegetable breeding, disease resistance, variety

\begin{abstract}
'Murasaki-29' sweetpotato [Ipomoea batatas (L.) Lam.] was developed by the Louisiana Agricultural Experiment Station to provide a specialty-type white flesh, dark purple skin cultivar with southern root-knot nematode and soil rot resistance. 'Murasaki29' produces excellent numbers of uniform plants (sprouts) early in the production season. 'Murasaki-29' matures later than 'Beauregard' in Louisiana. The roots in Louisiana can be elliptical, but often are round and sometimes splits occur. Production for fresh market is not anticipated in Louisiana as a result of its inconsistent appearance. In California, yields are competitive with other specialty white flesh types. Broad-spectrum disease resistance, including soil rot and southern rootknot nematode resistance, is desirable, and color and root shape are favorable.

Initially identified and evaluated as L0129 , the cultivar is named after the Japanese word for purple (murasaki). The dark purple skin is its most distinguishing characteristic and similar in coloration to the Japanese variety 'Kotobuki'.
\end{abstract}

\section{Origin}

'Murasaki-29' originated in 2001 as a seedling from an open-pollinated polycross nursery of the previous year. The female lineage is L89-72. L87-501 is the female parent of L89-72. The female parent of

Received for publication 24 Aug. 2007. Accepted for publication 8 Dec. 2007.

Approved for publication by the Director of the Louisiana Agricultural Experiment Station as manuscript no. 07-14-0376. Supported by state and matching funds allocated to the Louisiana State University Agricultural Center and the Louisiana Sweet Potato Advertising and Development Commission.

${ }^{1}$ Professor, School of Plant, Environmental and Soil Sciences.

${ }^{2}$ Associate Professor, Sweet Potato Research Station.

${ }^{3}$ Professor, Department of Plant Pathology and Crop Physiology.

${ }^{4}$ Professor, School of Plant, Environmental, and Soil Sciences.

${ }^{5}$ Farm Advisor, University of California Cooperative Extension.

${ }^{6}$ To whom reprint requests should be addressed; e-maildlabonte@agcenter.lsu.edu
L87-501 is L82-509. W-151 is the female parent of L82-509; W-151 was released as 'Southern Delite' (Jones et al., 1987).

\section{Description}

'Murasaki-29' has green-stemmed vines corresponding to color charts as $2.5 \mathrm{G}$ (green) $\mathrm{Y}$ (yellow) 5/4 (Munsell ${ }^{\circledR}$ Color, New Windsor, NY) from the apex to the crown of the roots. The canopy biomass is greater than those of 'Beauregard'. Unfolded immature leaves are dark green with slight purple abaxial venation [5 G (green) Y (yellow) (4/4)]. Leaf color changes little as they unfold. Adaxial color corresponds to $2.5 \mathrm{G}$ (green) Y (yellow) (4/4) and $2.5 \mathrm{G}$ (green) Y(yellow) (5/4) for the abaxial side. Slightly red margins disappear by the third open leaf. No red or purple pigmentation is present on petioles or stem nodes. Mature leaves have an acute apex and a cordate base. Leaves are glabrous, entire, and sometimes possess weak lobes (two at most). Leaves are similar in size to that of 'Beauregard'.

The calyx is composed of five green $[2.5 \mathrm{G}$ (green) Y (yellow) 8/4] elliptic 9.8-mm long sepals. The flower is mostly light purple [2.5R (red) P (purple) 6/2] on the exterior and darker in the throat of the corolla $[2.5 \mathrm{R}$ (red) $\mathrm{P}$ (purple) 3/8]. The stigma is purple [5R (red) $\mathrm{P}$ (purple) 6/6] and the stamens are inferior and attached to the ovary.

Storage roots vary in Louisiana from elliptic to round. Skin is dark purple [10 R (red) $\mathrm{P}$ (purple) 3/4] to a less intense purple [10 R (red) P (purple) 4/6] depending on soil type. Coloration is mostly retained in storage. The cortex is $5 \mathrm{~mm}$ in depth and the flesh is mostly white with a yellow cast [5 Y (yellow) 9/4]. Dry matter content is $\approx 30 \%$ to $32 \%$ depending on growing conditions.

\section{Disease Reactions}

'Murasaki-29' and 'Beauregard' have reacted similarly for most diseases we have evaluated in controlled tests. It is intermediate to resistant for soil rot caused by Streptomyces ipomoeae (Person \& W.J. Martin) Waksman \& Henrici. It is resistant to fusarium wilt or stem rot caused by Fusarium oxysporum Schlect. f. sp. batatas (Wollenw.) Snyd. \& Hans.; resistance is similar to 'Beau- regard'. In greenhouse tests that measure nematode reproduction, it is highly resistant to southern root-knot nematode, Meloidogyne incognita (Kofoid \& White 1919) Chitwood 1949 race 3; resistance is greater than for highly susceptible 'Beauregard'; reaction of 'Murasaki-29' to other races may vary. It is resistant to fusarium root rot caused by Fusarium solani (Sacc.) Mart. emend. Snyd. \& Hans., similar to 'Beauregard'. Storage roots are resistant to bacterial soft rot caused by Erwinia chrysanthemi Burkholder, McFadden \& Dimock; it is more resistant than 'Beauregard'. It is resistant to Rhizopus soft rot caused by Rhizopus stolonifer (Ehr. ex. Fr.) Lind. Incidence of circular spot, caused by Sclerotium rolfsii Sacc., has been low $(0 \%$ to $3 \%)$, similar to 'Beauregard' $(0 \%$ to $5 \%)$ in this reaction.

\section{Insect Resistance}

'Murasaki-29' has not been formally tested for relative insect resistance, but has not demonstrated any unusual propensity to insect damage in numerous on-farm trials.

\section{Production}

'Murasaki-29' was compared with 'Beauregard' in randomized complete block trials with three or four replications at various locations in Louisiana. There were two to five trials each year over a 3-year period (2004, 2005, and 2006) in Louisiana. These covered a wide range of planting dates and growing days. Yield and grade of 'Murasaki29 ' is typically less than that of 'Beauregard' (Table 1) in Louisiana and does not perform well when planted late. Differences between these cultivars in yield of U.S. \#1 grade roots were statistically significant $(P \leq 0.05)$ in two of the 18 trials, and 'Beauregard' produced the greater yield in both. Eight unreplicated trials of 'Murasaki-29' at various farms in California planted from mid-May to mid-July 2006 had yields ranging from $7.5 \mathrm{Mt} / \mathrm{ha}^{-1}$ of U.S. \#1 grade (5.1 to $8.9 \mathrm{~cm}$ diameter, 7.6 to $22.9 \mathrm{~cm}$ long) to $27.1 \mathrm{Mt} / \mathrm{ha}^{-1}$. Replicated trials conducted in 2005 and 2006 in California produced yields of 'Murasaki-29' at 15.5 and $15.1 \mathrm{Mt} \cdot \mathrm{ha}^{-1}$, respectively, for U.S. \#1 grade. On average, medium-grade (canners: 2.5 to $5.1 \mathrm{~cm}$ diameter, 5.1 to $17.8 \mathrm{~cm}$ long) yields were $10 \%$ less than U.S. \#1 grade yield. California trials in 2007 showed no significant difference between U.S. \#1 and medium (canner) grades for 'Murasaki-29' and 'Kotobuki' (Table 1). Most clones of 'Beauregard' yield more than 'Murasaki-29'; the combination of U.S. \#1 and mediumgrade yield for 'Murasaki-29' demonstrates reasonable productivity for a specialty type sweetpotato. 'Murasaki-29' will not directly compete with the dessert-type 'Beauregard' in the marketplace and is more similar to 'Kotobuki', another white flesh variety with little disease resistance. 'Murasaki-29' represents an adjunct to 'Kotobuki' and 'Murasaki-29' may prove valuable to growers given the stated disease resistance characteristics. 
Table 1. Average yield by grade of 'Murasaki-29' in replicated trials in Louisana and California

\begin{tabular}{|c|c|c|c|c|}
\hline \multirow[b]{2}{*}{ Cultivar } & \multirow[b]{2}{*}{ U.S. \# 1} & \multicolumn{3}{|c|}{ Avg. yield $\left(\mathrm{Mt}^{-} \mathrm{ha}^{-1}\right)^{\mathrm{zy}}$} \\
\hline & & Medium & Jumbo & Total marketable \\
\hline \multicolumn{5}{|l|}{$\overline{2004}$} \\
\hline Murasaki-29 & 11.8 & 9.8 & 1.1 & 22.7 \\
\hline Beauregard & 17.4 & 9.6 & 7.2 & 34.2 \\
\hline \multicolumn{5}{|l|}{2005} \\
\hline Murasaki-29 & 17.0 & 5.8 & 2.5 & 25.2 \\
\hline Beauregard & 17.1 & 7.7 & 13.9 & 38.7 \\
\hline \multicolumn{5}{|l|}{2006} \\
\hline Murasaki-29 & 12.9 & 5.0 & 9.2 & 27.1 \\
\hline Beauregard & 16.2 & 12.9 & 16.5 & 45.6 \\
\hline \multicolumn{5}{|l|}{2007} \\
\hline Murasaki-29 & 15.9 & 13.3 & 5.0 & 34.2 \\
\hline Kotobuki & 20.4 & 10.5 & 13.7 & 44.6 \\
\hline Beauregard & 29.2 & 8.9 & 27.5 & 65.6 \\
\hline
\end{tabular}

${ }^{\mathrm{z}}$ Average of five trials in 2004 (Louisiana), three in 2005 (Louisiana), two in 2006 (Louisiana), and one in 2007 (California).

${ }^{y}$ Sizes of roots: U.S. \#1: 5.1 to $8.9 \mathrm{~cm}$ diameter, 7.6 to $22.9 \mathrm{~cm}$ long; medium (canner): 2.5 to $5.1 \mathrm{~cm}$ diameter, 5.1 to $17.8 \mathrm{~cm}$ long; jumbo: larger than U.S. \#1 in diameter or length or both and without objectionable defects.

Plants of 'Murasaki-29' from propagation beds are early and prolific in comparison with 'Beauregard'. 'Murasaki-29' generally needs more time to harvest ( 1 to 2 weeks), partic- ularly when planted late. There is more variability in shape (round to elliptic) depending on soil types and environment in Louisiana; growth cracks also appear in some plots and reduce the marketable grade. Shape is mostly attractive in California: round elliptic and ovoid with a high level of uniformity. Splitting or growth cracks were not evident in any year or trial location.

White flesh 'Murasaki-29' has good culinary characteristics. It does not require any additional baking time in comparison with major dessert-type cultivars. It is characterized as slightly sweet with a somewhat flaky texture.

\section{Availability}

Limited quantities of foundation seed stock will be commercially available for the 2008 crop season. Requests for roots should be made to the Sweet Potato Research Station, P.O. Box 120, Chase, LA 71324. Intellectual property protection will be sought.

\section{Literature Cited}

Jones, A., P.D. Dukes, J.M. Schalk, M.G. Hamilton, and R.A. Baumgardner. 1987. 'Southern Delite' sweet potato. HortScience 22:329-330. 